\title{
Chronic autoimmune thyroiditis: a challenging clinical entity in surgical practice
}

\author{
S. Rajendra \\ Faculty of Medicine, University of Jaffna, Sri Lanka
}

Keywords: Thyroiditis; TPO antibody; FNAC; Ultrasound examination; associated malignancy

\begin{abstract}
Introduction

Chronic autoimmune thyroiditis is frequently encountered in surgical practice. However clinical data on chronic autoimmune thyroiditis has limited publications arising from Sri Lanka. This study presents our experience of this clinical entity which has differing thyroid morphologies and thyroid functional status at presentation.
\end{abstract}

\section{Objective}

The objective of this study was to analyse the spectrum of clinical profiles in patients with chronic auto immune thyroiditis attending at a surgical clinic. The clinical profiles analysed were the age and gender distribution, clinical presentation, thyroid functional status, thyroid peroxidase antibody (TPO Ab) status, Fine Needle Aspiration Cytology (FNAC) findings, Ultrasonographic (USS) assessment and association of thyroid malignancies. Formulation of a diagnostic guideline was also considered.

\section{Study design}

This is an observational study using the clinical profiles of patients with thyroid diseases registered in the surgical clinic from January 2009 to December 2018. Patients diagnosed to have chronic auto immune thyroiditis were included in this study. Different clinical profiles of these patients were analyzed.

\section{Results}

Out of 226 patients with thyroid diseases registered to the surgical clinic over a decade, 89 (39.4\%) had chronic auto immune thyroiditis confirmed by either TPO Ab or FNAC or by both. Thyroid morphology and thyroid functional states of patients with chronic auto immune thyroiditis at presentation varied widely; $57.3 \%, 27 \%$ and $15.7 \%$ had diffuse goitre, multinodular goitre and solitary nodule respectively and

\footnotetext{
Correspondence: S.Rajendra

E-mail: dr.s.rajendra@gmail.com

Received: 28-11-2019 Accepted: 30-12-2019

(iD) https://orcid.org/0000-0002-3303-603X DOI: http://doi.org/10.4038/sljs.v37i4.8656
}

$66.3 \%, 28.1 \%$ and $5.6 \%$ were hypothyroid, euthyroid and hyperthyroid state respectively. An USS of thyroid gland performed on 83 patients revealed sonographic features suggestive of thyroiditis in 67 patients (75.2\%). The association between USS detected chronic autoimmune thyroiditis and the presence of hypothyroid state at presentation was statistically significant $(p=0.027)$. Associated thyroid malignancies were detected in thyroidectomy specimens of 6 patients; 5 were papillary and one was follicular carcinoma.

\section{Conclusion}

The thyroid morphology and functional status are not unique in patients with chronic autoimmune thyroiditis. There is a risk of having associated thyroid malignancy. USS evaluation of patients could be included in the guideline for diagnosis to mitigate the challenges faced in the surgical management of chronic autoimmune thyroiditis.

\section{Introduction}

Chronic autoimmune thyroiditis is a common clinical problem encountered in surgical practice. Many of them presents with goitrous hypothyroidism (1). Chronic autoimmune thyroiditis has a prevalence rate of $1-4 \%$ and incidence of 3-6/10000 population per year in the western world (2). The data on thyroiditis in Sri Lanka is sparse and precise incidence and prevalence is not known. Widespread use of iodized salt could cause increasing incidence of thyroiditis (1). Females of middle age are predominantly affected by chronic autoimmune thyroiditis (3).Clinical presentation of chronic auto immune thyroiditis varies widely and thyroid auto antibodies such as anti thyroid peroxidase antibody (TPO Ab) and Fine Needle Aspiration Cytology( FNAC) assessment have been used to confirm the diagnosis (4). Differentiated thyroid carcinomas and thyroid lymphomas have been associated with chronic autoimmune thyroiditis (5).

\section{Background}

The fist line investigation to confirm chronic auto immune thyroiditis is TPO Ab estimation. This was not available in Teaching Hospital Jaffna during the study period. As it is an expensive investigation at private laboratories, all clinically 
suspected patients with chronic auto immune thyroiditis were not requested for TPO $\mathrm{Ab}$ estimation. FNAC is an invasive investigation and the gold standard for diagnosing chronic auto immune thyroiditis. Though it was available in Teaching Hospital Jaffna, was difficult to perform in thyroiditis patients with small and atrophic thyroid glands.

Ultra Sound Scan assessment of thyroid is a noninvasive investigation, which not only identifies chronic auto immune thyroiditis but also could provide information about nodules suspicious of malignancy.

There are no clear guidelines in the management of chronic autoimmune thyroiditis and decision making in these patient could be challenging. This study aimed to formulate a suitable diagnostic guideline for effective surgical management based on the analyses of the spectrum of clinical profiles in patients with chronic auto immune thyroiditis.

\section{Study design}

This is an observational study, that has been carried out in a single surgical clinic of Department of Surgery, Teaching Hospital Jaffna from January, 2009.

Clinical profiles of patients with thyroid diseases registered in the surgical clinic from January 2009 to December 2018 were maintained in a database. Patients diagnosed with chronic auto immune thyroiditis were included in this study.

Clinical profiles analysed were the biographical data (age and sex) of patients, presenting complaints (including symptoms of altered thyroid function, musculoskeletal and neuropsychiatric symptoms), clinical signs related to altered thyroid function and thyroid morphology (diffuse, solitary nodule and multinodular goitre), investigation results (TPO, FNAC,USS) and histopathology reports of thyroid specimens of patients who underwent thyroidectomy.

TSH (thyroid stimulating hormone) (normal values 0.27-5.5 $\mathrm{IU} / \mathrm{ml})$, FNAC and USS of thyroid were carried out at the Pathology and Radiology Departments of Teaching Hospital Jaffna. Anti thyroid peroxidase (anti TPO) (normal values $<35 \mathrm{IU} / \mathrm{ml}$ ) was performed in those patients who were affordable and were willing to do it in private sector. It was estimated by ELISA(Enzyme Linked Immunosorbent Assay) method, using USA made BRIO Elisa analyzer reagent kit.

Different clinical profiles of chronic autoimmune thyroiditis were compared with local and international data to find out any unique difference in the prevalence of clinic-pathological parameters in the region. Statistical analysis of clinical parameters were done using IBM SPSS 21 and p-value $<0.05$ was considered as statistically significant.

\section{Results}

Total number of patients with thyroid diseases registered to the surgical clinic over a decade was 226. Among them 140 patients had clinical suspicion of chronic auto immune thyroiditis and of them 89 had chronic auto immune thyroiditis confirmed by TPO Ab or by FNAC or by both.

Age and sex distribution of patients diagnosed to have chronic auto immune thyroiditis.

Among the 89 patients with chronic auto immune thyroiditis, there were $83(93.3 \%)$ females and 6(6.7\%) male patients and the mean age of 39.27 years (ranging from 13 to 69 years).

Table 1. Age and sex distribution of patients with thyroiditis

\begin{tabular}{|l|l|l|l|}
\hline Age group & No of patients $(n=89)$ & Female & Male \\
\hline $1-20$ years & $8(8.9 \%)$ & $8(8.9 \%)$ & $0(0 \%)$ \\
\hline $21-40$ years & $41(46 \%)$ & $38(42.7 \%)$ & $3(3.4 \%)$ \\
\hline $41-60$ years & $34(38.2 \%)$ & $32(38.2 \%)$ & $2(2.2 \%)$ \\
\hline $61-80$ years & $6(6.7 \%)$ & $5(5.6 \%)$ & $1(1.1 \%)$ \\
\hline
\end{tabular}

Clinical presentation of patients with chronic autoimmune thyroiditis in this study

Table 2. Spectrum of presenting problem in patients with thyroiditis

\begin{tabular}{|l|l|}
\hline Presenting problem & No of patients (n=89) \\
\hline Neck lump only & $73(82 \%)$ \\
\hline $\begin{array}{l}\text { Neck lump + Musculo skeletal } \\
\text { symptoms }\end{array}$ & $2(2.2 \%)$ \\
\hline Neck lump + Hypothyroid features & $5(5.6 \%)$ \\
\hline Painful neck lump & $9(10.1 \%)$ \\
\hline
\end{tabular}

Thyroid morphology of patients with chronic autoimmune thyroiditis in this study

Table 3. Spectrum of thyroid morphology in patients with thyroiditis

\begin{tabular}{|l|c|}
\hline Morphology & No of patients (n=89) \\
\hline Diffuse goitre & $51(57.3 \%)$ \\
\hline Solitary nodule & $14(15.7 \%)$ \\
\hline MNG & $24(27.0 \%)$ \\
\hline
\end{tabular}

Thyroid functional status of patients with chronic auto immune thyroiditis in this study 
Euthyroidism has been defined as TSH levels within the reference range of $0.32-5.06 \mathrm{mIU} / \mathrm{L}(0.32 \leq \mathrm{TSH} \leq 5.06)$. Other thyroid test results such as TSH $>5.06 \mathrm{mIU} / \mathrm{L}$ and FT4 of $0.91-1.55 \mathrm{ng} / \mathrm{dL}, \mathrm{TSH}>5.06 \mathrm{mIU} / \mathrm{L}$ and $\mathrm{FT} 4<0.91 \mathrm{ng} / \mathrm{dL}$, $\mathrm{TSH}<0.32 \mathrm{mIU} / \mathrm{L}$ and FT4 between $0.91-1.55 \mathrm{ng} / \mathrm{dL}$, $\mathrm{TSH}<0.32 \mathrm{mIU} / \mathrm{L}$ and FT4 $>1.55(\mathrm{ng} / \mathrm{dL})$ were considered as subclinical hypothyroidism, overt hypothyroidism, subclinical hyperthyroidism and overt hyperthyroidism, respectively (6). In our study subclinical hypothyroidism and overt hypothyroidism were considered as hypothyroidism and subclinical hyperthyroidism and overt hyperthyroidism were considered as hyperthyroidism.

Table 4. Distribution of thyroiditis patients according to thyroid functional status

\begin{tabular}{|l|c|c|c|}
\hline $\begin{array}{l}\text { Thyroid functional } \\
\text { status }\end{array}$ & $\begin{array}{c}\text { No of patients } \\
\text { (n=89) }\end{array}$ & Female & Male \\
\hline Euthyroid & $25(28 \%)$ & 23 & 2 \\
\hline Hypothyroid & $59(66 \%)$ & 55 & 4 \\
\hline Hyperthyroid & $5(6 \%)$ & 5 & 0 \\
\hline
\end{tabular}

$66 \%$ of patients with chronic auto immune thyroiditis were hypothyroid at presentation

TPO Ab in patients with chronic autoimmune thyroiditis in this study

$\mathrm{TPO} \mathrm{Ab}$ estimation is the first line investigation to confirm the diagnosis of chronic autoimmune thyroiditis. Among 89 patients with chronic autoimmune thyroiditis, only 38 patients got their TPO Ab estimation done.

Table 5. Distribution of patients with thyroiditis according to TPOAb status

\begin{tabular}{|l|r|c|c|c|}
\hline \multicolumn{2}{|c|}{ TPO Ab status } & $\begin{array}{c}\text { Number of } \\
\text { patients }\end{array}$ & Female & Male \\
\hline $\begin{array}{l}\text { Test } \\
\text { performed } \\
(n=38)\end{array}$ & Positive & 35 & 32 & 3 \\
\cline { 2 - 5 } & Negative & 3 & 3 & \\
\hline \multicolumn{2}{|l|}{ Test not performed } & 51 & 48 & 3 \\
\hline
\end{tabular}

Out of 38 patients who had their TPO Ab test done 35(92.1\%), had positive results (TPO Ab + )

FNAC of thyroid in patients with chronic autoimmune thyroiditis in this study

FNAC was performed to 80 patients at the Department of Pathology. Since TPO Ab test was not available at TH Jaffna, FNAC was the mainstay of investigation to confirm thyroiditis.
Table 6. Spectrum of FNAC findings in patients with thyroiditis

\begin{tabular}{|l|r|c|}
\hline \multicolumn{2}{|l|}{ FNAC finding } & No of patients (n=89) \\
\hline \multirow{3}{*}{$\begin{array}{l}\text { FNAC } \\
\text { performed }\end{array}$} & Thyroiditis & $76(85.4 \%)$ \\
\cline { 2 - 3 } & Colloid nodule & $2(2.2 \%)$ \\
\cline { 2 - 3 } & Normal thyroid & $2(2.2 \%)$ \\
\hline \multicolumn{2}{|l|}{ FNAC not performed } & $9(10.2 \%)$ \\
\hline
\end{tabular}

80 patients had their FNAC done and 76 of them $(95 \%)$ had cytological evidence of chronic autoimmune thyroiditis.

Table 7. Thyroiditis patient distribution based on FNAC and TPOAb $(n=29)$

\begin{tabular}{|l|c|c|}
\hline FNAC & TPO Ab + & TPO Ab - \\
\hline Thyroiditis + & 22 & 3 \\
\hline Thyroiditis - & 4 & 0 \\
\hline
\end{tabular}

29 patients had both FNAC and TPO Ab tests done. 4 of them who did not have FNAC evidence of chronic autoimmune thyroiditis had TPO Ab in their serum. 3 of them who had FNAC evidence of chronic autoimmune thyroiditis did not have TPOAb in their serum.

Table 8. Association of diagnostic investigations with thyroid functional state

\begin{tabular}{|c|c|c|c|c|c|c|c|}
\hline \multirow{2}{*}{$\begin{array}{l}\text { Investigation } \\
\text { Thyroiditis }\end{array}$} & & \multicolumn{2}{|c|}{$\begin{array}{c}\text { TPO } \\
(n=38)\end{array}$} & \multicolumn{2}{|c|}{$\begin{array}{l}\text { FNAC } \\
(n=80)\end{array}$} & \multicolumn{2}{|c|}{$\begin{array}{c}\text { USS } \\
(n=83)\end{array}$} \\
\hline & & + & - & + & - & + & - \\
\hline \multirow{3}{*}{$\begin{array}{l}\text { Thyroid } \\
\text { Functional } \\
\text { State }\end{array}$} & Euthyroid & 10 & 01 & 23 & 01 & 18 & 06 \\
\hline & Hypothyroid & 24 & 02 & 49 & 03 & 47 & 07 \\
\hline & Hyperthyroid & 01 & 00 & 04 & 00 & 02 & 03 \\
\hline Not done & & \multicolumn{2}{|c|}{51} & \multicolumn{2}{|c|}{9} & \multicolumn{2}{|c|}{6} \\
\hline
\end{tabular}

Among the 35 patients with positive TPO Ab test, 24 $(68.6 \%)$ were hypothyroid at presentation. 
There was no statistically significant association between TPO Ab status and the thyroid functional state of patients (Fisher's exact test $\mathrm{p}$-value $=1.0$ ).

Out of 76 patients who had cytological evidence of chronic autoimmune thyroiditis 49 patients $(61.25 \%)$ were hypothyroid at presentation $(\mathrm{p}=0.856)$.

Among the 89 diagnosed patients, 83 had their USS assessment of thyroid gland. 67 patients $(75.2 \%)$ with chronic autoimmune thyroiditis had USS features suggestive of the diagnosis. Sixteen patients (17.9\%) did not have USS features suggestive of thyroiditis. Six patients $(6.7 \%)$ did not have an USS assessment of thyroid. The association between USS detected chronic autoimmune thyroiditis and the presence of hypothyroid state at presentation was statistically significant $(p=0.027)$.

\section{Associated thyroid malignancies in chronic autoimmune} thyroiditis patients

Among the 89 patients with chronic autoimmune thyroiditis, 12 underwent thyroidectomy and the histopathology reports were analysed. Three patients $(3.4 \%)$ with chronic autoimmune thyroiditis had associated papillary thyroid carcinomas. Furthermore, of 21 patients who were clinically suspicious of chronic autoimmune thyroiditis without TPO $\mathrm{Ab}$ and FNAC confirmation, 4 underwent thyroidectomy for suspicious thyroid nodule on USS evaluation. Histopathology report of three of these thyroid gland specimens revealed the presence of thyroid malignancy with chronic autoimmune thyroiditis; two were papillary carcinomas and one was a follicular carcinoma.

Hence, overall thyroid malignancies were detected in association with chronic auto immune thyroiditis in 6 thyroidectomy specimens; 5 were papillary and one was follicular carcinoma.

\section{Discussion}

The term "thyroiditis" includes a group of heterogeneous disorders characterized by inflammation of thyroid gland. Thyroiditis predominantly affects women. The clinical course of thyroiditis may be chronic, subacute and acute, depending on the underlying cause (5). Chronic thyroiditis includes chronic autoimmune thyroiditis and Riedel's Thyroiditis. Subacute thyroiditis includes painless postpartum thyroiditis, painless sporadic thyroiditis \& painful sub-acute thyroiditis whereas acute thyroiditis will encompass acute suppurative thyroiditis (7).

Chronic autoimmune thyroiditis, painless postpartum thyroiditis and painless sporadic thyroiditis have an autoimmune basis (8).
Dr. Hakuru Hashimoto described enlargement and lymphoid transformation of thyroid in 4 women in 1912 ("struma lymphomatosa") and identified antithyroid antibodies. This was named Hashimoto's disease or Hashimoto's thyroiditis, which is currently classified as chronic autoimmune thyroiditis (8).

Chronic autoimmune thyroiditis has two clinical forms, a goitrous form and an atrophic form. Both are characterized by the presence of thyroid auto antibodies in serum and by varying degrees of thyroid dysfunction; they differ only in the presence or absence of goitre (8). About $10 \%$ of patients with chronic autoimmune hypothyroidism have atrophic thyroid gland (7).

Table 9. Comparison of epidemiological data on thyroiditis with other regional studies

\begin{tabular}{|c|c|c|c|}
\hline Country & $\begin{array}{l}\% \text { of total } \\
\text { patients with } \\
\text { thyroid disease }\end{array}$ & $\begin{array}{l}\text { Female : } \\
\text { Male }\end{array}$ & $\begin{array}{l}\text { Mean age in } \\
\text { years }\end{array}$ \\
\hline $\begin{array}{l}\text { USA (9) } \\
\text { Staii et al }\end{array}$ & $13.4 \%$ & $11.7: 1$ & 47 \\
\hline $\begin{array}{l}\text { India }(10,11) \\
\text { Thomas et al } \\
\text { Sood et al }\end{array}$ & $\begin{array}{l}\text { Not available } \\
31.4 \%\end{array}$ & $\begin{array}{l}8.6: 1 \\
10: 1\end{array}$ & $\begin{array}{l}34.18 \\
\text { (range 21-30) }\end{array}$ \\
\hline $\begin{array}{l}\text { Sri Lanka }(1,3) \\
\text { Samarawiclarama et al } \\
\text { Siriweera et al } \\
\text { Rajendra }\end{array}$ & $\begin{array}{l}12 \% \\
5.9 \% \\
39.4 \%\end{array}$ & $\begin{array}{l}42: 1 \\
10.3: 1 \\
13.8: 1\end{array}$ & $\begin{array}{l}33 \\
43.3 \\
39.27\end{array}$ \\
\hline
\end{tabular}

The prevalence of chronic autoimmune thyroiditis among the patients with thyroid diseases in this study in Jaffna is relatively high when compared to the data with loco regional studies.

Table 10. Comparison of clinical presentation of thyroiditis with other regional studies

\begin{tabular}{|l|c|c|}
\hline $\begin{array}{l}\text { Clinical presentation of } \\
\text { patients with chronic } \\
\text { autoimmune thyroiditis }\end{array}$ & $\begin{array}{c}\text { \% of patients in } \\
\text { loco-regional studies } \\
\mathbf{( 1 0 , 1 2 )}\end{array}$ & $\begin{array}{c}\% \text { of patients } \\
\text { in this study in } \\
\text { Jaffna }\end{array}$ \\
\hline Neck lump only & $\begin{array}{c}69.4 \% \\
\text { (Thomas et al, India ) }\end{array}$ & $82 \%$ \\
\hline $\begin{array}{l}\text { Neck lump + Musculo } \\
\text { skeletal symptoms }\end{array}$ & $\begin{array}{c}25.5 \% \\
\text { (Becker et al, USA) }\end{array}$ & $2.2 \%$ \\
\hline $\begin{array}{l}\text { Neck lump + Hypothyroid } \\
\text { features }\end{array}$ & $\begin{array}{c}8.3 \% \\
\text { (Thomas et al, India ) }\end{array}$ & $5.6 \%$ \\
\hline
\end{tabular}

Most common presentation of patients with chronic autoimmune thyroiditis in Jaffna was goitre (neck lump) and only very few had musculoskeletal symptoms when compared with studies in loco-regional countries. Patients with chronic autoimmune thyroiditis presenting with hypothyroid symptoms at presentation were comparable to 
that in India. Though patients with chronic autoimmune thyroiditis characteristically presents with painless neck lump, in $10.1 \%$ of the patients in this study presented with painful neck lump.

Table 11. Comparison of thyroid morphology with other regional studies

\begin{tabular}{|c|c|c|c|c|}
\hline \multirow[t]{2}{*}{ Country } & \multicolumn{3}{|c|}{ Goitre } & \multirow[t]{2}{*}{ No goitre } \\
\hline & Diffuse & MNG & STN & \\
\hline India $(13,10)$ & & & & \\
\hline $\begin{array}{l}\text { Chandanwale et al } \\
(n=110) \\
\text { Thomas et al } \\
(n=144)\end{array}$ & $\begin{array}{l}66.3 \% \\
47.2 \%\end{array}$ & $\begin{array}{l}30.9 \% \\
19.4 \%\end{array}$ & $\begin{array}{l}2.7 \% \\
2.7 \%\end{array}$ & $\begin{array}{c}- \\
30.5 \%\end{array}$ \\
\hline Srilanka (1) & & & & \\
\hline $\begin{array}{l}\text { Samarawickrama } \\
\text { et al ( } n=43 \text { ) } \\
\text { Rajendra }(n=89)\end{array}$ & $\begin{array}{l}23.3 \% \\
57.3 \%\end{array}$ & $\begin{array}{l}48.8 \% \\
27.0 \%\end{array}$ & $\begin{array}{l}20.9 \% \\
15.7 \%\end{array}$ & $\begin{array}{l}7 \% \\
-\end{array}$ \\
\hline
\end{tabular}

Keeping in par with the loco-regional studies, diffuse goitre is the characteristic thyroid morphology in patients with chronic autoimmune thyroiditis in Jaffna. Anyhow, patients with chronic autoimmune thyroiditis in Jaffna presenting with solitary nodule of thyroid is not uncommon.

Table 12. Comparison of thyroid functional status with other regional studies

\begin{tabular}{|c|c|c|c|}
\hline \multirow[b]{2}{*}{ Country } & \multicolumn{3}{|c|}{ Thyroid functional status based on TSH } \\
\hline & Hyperthyroid & Euthyroid & Hypothyroid \\
\hline $\begin{array}{l}\mathrm{USA}(9) \\
\text { Staii et al }(\mathrm{n}=102)\end{array}$ & None & $46 \%$ & $54 \%$ \\
\hline $\begin{array}{l}\text { India (10) } \\
\text { Thomas et al }(n=140)\end{array}$ & $21.4 \%$ & $32.8 \%$ & $45.7 \%$ \\
\hline $\begin{array}{l}\text { Sri Lanka (1) } \\
\text { Samarawickrama et al } \\
(\mathrm{n}=43) \\
\text { Rajendra }(\mathrm{n}=89)\end{array}$ & $\begin{array}{l}2.3 \% \\
5.6 \%\end{array}$ & $\begin{array}{l}48.8 \% \\
28.1 \%\end{array}$ & $\begin{array}{l}48.8 \\
66.3 \%\end{array}$ \\
\hline
\end{tabular}

Majority of patients with chronic autoimmune thyroiditis in this study in Jaffna had hypothyroidism at presentation.

More patients with chronic autoimmune thyroiditis have high serum TPOAb than thyroglobulin antibody (14). TPO Ab is also found in sera of about $10 \%$ of normal adults, with an increasing prevalence (up to $30 \%$ ) in older adults and thus low titers of TPO Ab is not specific for diagnosis (15). TPO Ab is directly involved in thyroid cells damage and positively correlated with the activity of chronic autoimmune thyroiditis (15). TPO Ab is found in over $90 \%$ of patients with autoimmune hypothyroidism (16).
A distinctive characteristic, supporting the clinical diagnosis of chronic autoimmune thyroiditis, is the presence of TPO Ab. Anyhow; it is present only in $50 \%$ of chronic autoimmune thyroiditis patients who are euthyroid (17). When chronic autoimmune thyroiditis is suspected clinically, a test for TPO $\mathrm{Ab}$ and measurement of the serum TSH (thyrotropin) concentration are generally sufficient to confirm the diagnosis (8).

Table 13. Comparison of TPO Ab and thyroid functional state with other regional studies

\begin{tabular}{|l|r|r|}
\hline Country & $\begin{array}{l}\text { Patients with } \\
\text { TPO Ab + }\end{array}$ & $\begin{array}{l}\text { Patients with TPO Ab + } \\
\text { who have Hypothyroidism }\end{array}$ \\
\hline $\begin{array}{l}\text { USA } \\
\text { Staii et al (9) }\end{array}$ & 29 & $21(72.4 \%)$ \\
\hline $\begin{array}{l}\text { Iran } \\
\text { Ghoraishian et al(15) }\end{array}$ & 866 & $281(32.4 \%)$ \\
\hline $\begin{array}{l}\text { India } \\
\text { Sood et al (11) }\end{array}$ & 61 & $42(68.8 \%)$ \\
\hline $\begin{array}{l}\text { Sri Lanka } \\
\text { Rajendra }\end{array}$ & 35 & $24(68.6 \%)$ \\
\hline
\end{tabular}

Prevalence of hypothyroidism in TPO Ab positive patients in this study in Jaffna seems similar to that in loco-regional countries except that found in Iran.

\section{FNAC assessment of chronic autoimmune thyroiditis}

Fine Needle Aspiration Cytology (FNAC) is considered as the gold standard technique to diagnose chronic auto immune thyroiditis (13).

Hurthle (oxyphilic) cell change, infiltration of follicles by lymphocytes / plasma cells, epithelioid granuloma with giant cells and lymphoid follicle formation and moderate amount of background colloid are the features characteristic of chronic auto immune thyroiditis (Hashimoto's thyroiditis) (18).

Fine needle aspiration cytology (FNAC) has an accuracy rate of $92 \%$ in diagnosing chronic autoimmune thyroiditis (19). FNAC can miss the diagnosis of chronic auto immune thyroiditis in few cases due to inherent limitations of this procedure and also due to varying cytomorphological features such as with other lesions like multinodular goiter with degenerative changes, follicular neoplasm, Hurthle cell neoplasm, papillary carcinoma, reactive lymphnode and lymphoma (20).

FNAC can have false negative and false positive rates. The false negative rate (FNR) is the percentage of patients reported to have benign cytology by FNAC, who are found to have a malignant lesion confirmed on thyroidectomy. FNR ranges from 1.5 to $11.5 \%$. The false positive rate (FPR) is the percentage of patients reported to have thyroid malignancy by 
FNAC, who are found to have a benign lesion on histological examination. FPR ranges from $1.2 \%$ to $6 \%$ (19).

In this study in Jaffna, 80 patients diagnosed to have chronic autoimmune thyroiditis underwent FNAC assessment and 76 of them (95\%) had cytological evidence lymphocyte infiltration. In a study carried out in India, 55 out of $65(84.6 \%)$ patients had cytological evidence lymphocyte infiltration (11).

\section{FNAC and hypothyroidism}

Table 14. Comparison of FNAC and hypothyroidism with regional studies

\begin{tabular}{|l|l|}
\hline Country & FNAC + and elevated TSH \\
\hline $\begin{array}{l}\text { USA } \\
\text { Staii et al(9) }\end{array}$ & $53.9 \%$ \\
\hline $\begin{array}{l}\text { India } \\
\text { Sood et al (11) }\end{array}$ & $63.07 \%$ \\
\hline $\begin{array}{l}\text { Sri Lanka } \\
\text { Rajendra }\end{array}$ & $64.5 \%$ \\
\hline
\end{tabular}

FNAC and TPOAb

Table 15. Comparison of FNAC and TPO Ab status with other regional studies

\begin{tabular}{|l|l|}
\hline Country & FNAC + and TPO Ab + \\
\hline USA (9) & $65 \%$ \\
\hline Indii et al & \\
\hline Sood et al (11) & $78.5 \%$ \\
\hline Thomas et al(10) & $87.7 \%$ \\
\hline Sri Lanka & \\
Colombo & $65 \%$ \\
Fernando et al(21) & \\
Jaffna & $75.8 \%$ \\
Rajendra & \\
\hline
\end{tabular}

Lymphocytes that can produce antithyroid antibodies could be found in the thyroid glands of patients with chronic autoimmune thyroiditis without evidence of a peripheral immune response (ie TPO $\mathrm{Ab}-\mathrm{ve}$ and FNAC + ve). This suggests that the possibility of chronic autoimmune thyroiditis to exist as an organ-restricted autoimmune disorder (22). Three patients who had FNAC evidence of chronic autoimmune thyroiditis in this study did not have $\mathrm{TPO} A b$ in their serum.

Sometimes there is lack of correlation between TPO Ab levels and FNAC diagnosis of chronic autoimmune thyroiditis especially in children and young adult patients. This could be because that in early stage of disease, antibody production is confined to intrathyroidal lymphocytes (Organ restricted). Likewise some patients with significant titres of TPO Ab may not have FNAC proven chronic autoimmune thyroiditis (ie TPO Ab + ve and FNAC - ve). This could be due to the fact that focal lymphocytic thyroiditis (Focal Auto Immune Thyroid Disease) which is an early lesion that can be missed by FNAC (10). Four patients who did not have FNAC evidence of chronic autoimmune thyroiditis in this study had $\mathrm{TPO} \mathrm{Ab}$ in their serum.

\section{Ultrasonographic assessment of thyroid in patients with chronic auto immune thyroiditis}

Characteristic USS findings in chronic autoimmune thyroiditis are hypo-echogenicity, coarse echo-texture, increased vascularity and micronodules. Echogenicity of thyroid is compared to the strap muscles. Normal thyroid gland is uniformly hyperechoic. In chronic autoimmune thyroiditis the thyroid gland is classified as hypoechoic as its echogenicity will be equal to or less than the strap muscles. Normal thyroid has fine echo-texure whereas it will have coarsened echotexture in chronic autoimmune thyroiditis. Nodules in Hashimoto's thyroiditis are known as micronodules and their size will be $\leq 6 \mathrm{~mm}$. Although the other similar nodules that are hyper and hypoechoic are included as micronodules yet the solitary nodules and dissimilar nodules are not classified as micronodules. Colour Doppler is used to assess thyroid vascularity (23).

Hypoechogenicity and increased vascularity are most sensitive parameters to diagnose Hashimoto's thyroiditis where as micronodules were most specific parameter for the diagnosis. Coarsened echo texture has an intermediate sensitivity and specificity for diagnosis of Hashimoto's thyroiditis by ultrasonography (23). The USS examination is $78.5 \%$ sensitive and $95.2 \%$ specific in diagnosing chronic autoimmune thyroiditis. The positive and negative predictive values of USS examination for chronic autoimmune thyroiditis are $88 \%$ and $90.9 \%$, respectively. The overall accuracy of USS in diagnosing chronic autoimmune thyroiditis is $90.1 \%$ (23). It was $74.2 \%$ in this study.

\section{Need for a guideline to assess patients with chronic auto immune thyroiditis}

In a study performed at a tertiary hospital in Sri Lanka, it was shown that the sensitivity of ultrasonography in diagnosing thyroiditis was $89.47 \%$ while the specificity was $96.3 \%$. Its positive predictive value was $94.4 \%$ (24). Features 


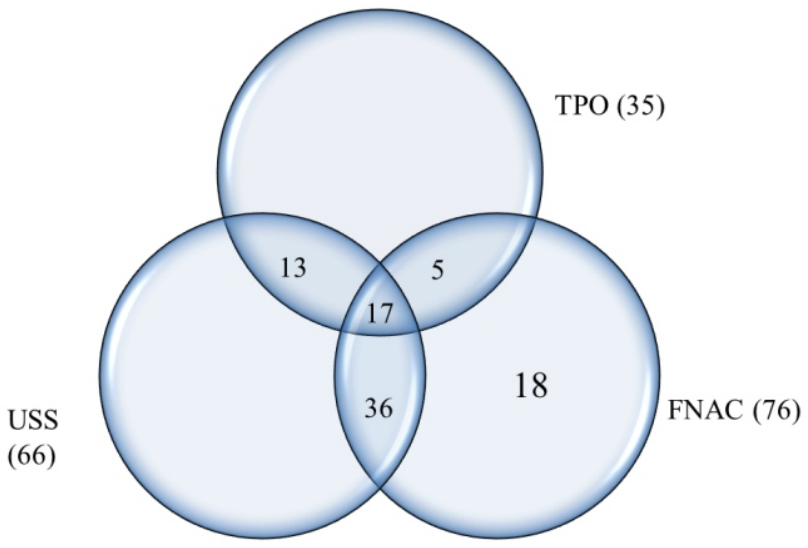

Figure 1. Positive investigation results among thyroiditis patients in this study at a glance

considered to suggest malignancy in a thyroid nodule are hypoechogenicity, solid consistency, greater nodular height than width, presence of micro calcifications, absence of peripheral halos or presence of an interrupted halo, presence of intranodular vascularity and presence of peripheral vascularity. It has also been shown that combination of these ultrasonographic characteristics will improve the diagnostic accuracy of identifying malignant nodules in thyroid (24).

In this study, 4 patients underwent thyroidectomy for suspicious nodule on USS evaluation. Histopathology report of three thyroid gland specimens of these patients revealed the presence of thyroid malignancy with chronic auto immune thyroiditis. These three patients did not have positive finding in either TPO Ab or FNAC test.
As chronic autoimmune thyroiditis has a risk of associated malignancy it could be useful to have guidelines for its diagnosis and management.

Suggested guideline for diagnosing patients with chronic autoimmune thyroiditis

TPO Ab, USS and thyroid function tests (TFT) can be used to evaluate chronic autoimmune thyroiditis and FNAC can be performed on any suspicious lesion to detect existence of associated malignancy.

\section{Conclusions}

The following conclusions could be made from this study on the spectrum of clinical profiles in chronic autoimmune thyroiditis in a cohort of patients from Jaffna:

- The thyroid morphology and functional status are not unique in patients with chronic autoimmune thyroiditis.

- Females are mostly affected especially in the 20-40 years of age.

- Many of the patients have diffuse goitre and hypothyroidism at presentation.

- There is a risk of having associated thyroid malignancy.

- USS evaluation of patients could be included in the guideline for diagnosis.

\section{Limitations}

- The study was conducted in a single surgical clinic and this may not represent the entire patient population with thyroid diseases in Jaffna.

\section{Diagnosis of Chronic Autoimmune Thyroiditis (Hashimoto's thyroiditis)}

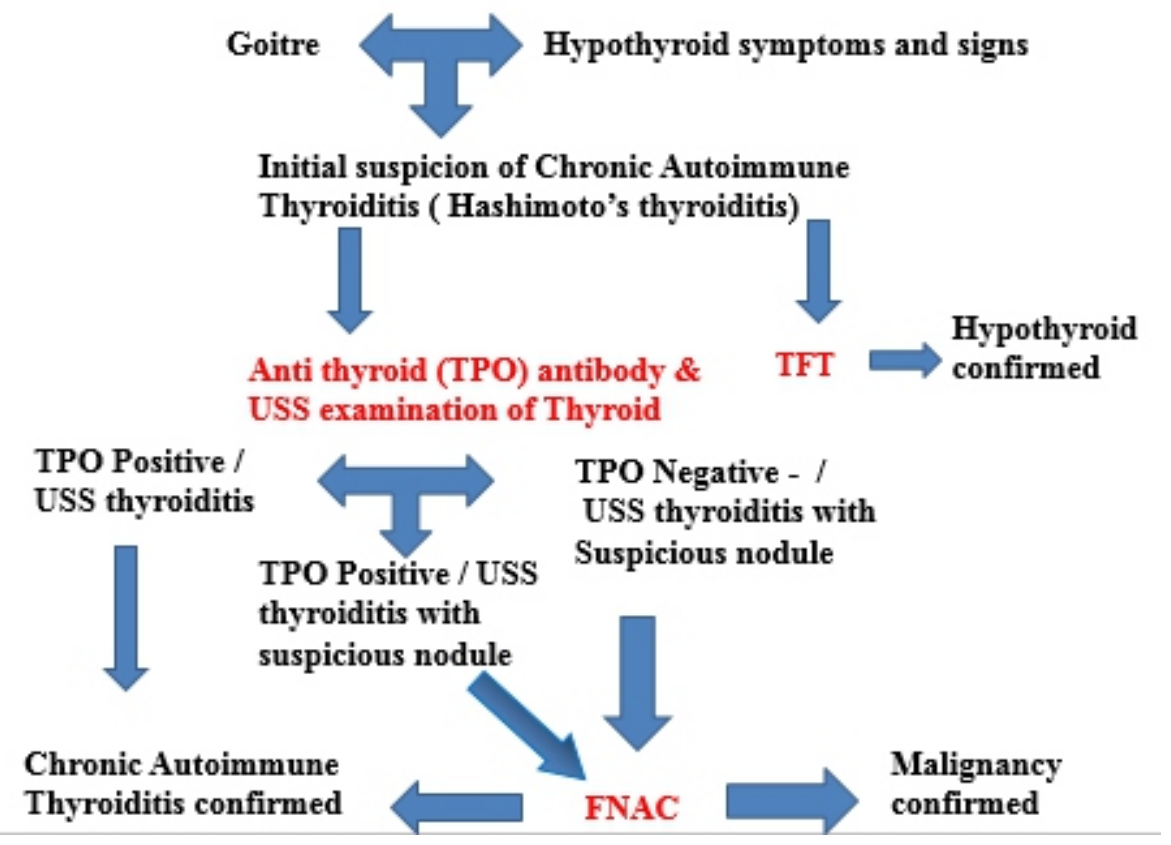

Figure 2. Suggested guideline for diagnosing patients with chronic autoimmune thyroiditis 
- TPO antibody test was not performed in all cases clinically suspected to have chronic autoimmune thyroiditis.

- The yield of FNAC of thyroid may differ according to the experience of the cytologist.

- The USS assessment for thyroiditis may be subjected to observer variations.

\section{Recommendations}

A larger population study is warranted for further evaluation of above conclusions and finalizing the diagnostic guideline for chronic autoimmune thyroiditis.

All authors disclose no conflict of interest. The study was conducted in accordance with the ethical standards of the relevant institutional or national ethics committee and the Helsinki Declaration of 1975, as revised in 2000 .

\section{References}

1. Samarawickrama MB, Perera BL. Thyroiditis: can we depend on the clinical features to diagnose?. Galle Medical Journal. 2009 Oct 8;14(1). https://doi.org/10.4038/gmj.v14i1.1171

2. Krishna M. Cytomorphological and biochemical correlation in thyroiditis. Thyroid. 2003; 13:485-9.

3. Siriweera EH, Ratnatunga NV. Profile of Hashimoto's thyroiditis in Sri Lankans: is there an increased risk of ancillary pathologies in Hashimoto's thyroiditis?. Journal of thyroid research. 2010;2010. https://doi.org/10.4061/2010/124264

4. Parvathaneni A, Fischman D, Cheriyath P. Hashimoto's thyroiditis. InA New Look at Hypothyroidism 2012 Feb 17. IntechOpen. https://doi.org/10.5772/30288

5. Bates M, Allahabadia A. Thyroiditis. Surgery (Oxford). 2003 Dec 1;21(12):303-4 https://doi.org/10.1383/surg.21.12.303.25165

6. Amouzegar A, Gharibzadeh S, Kazemian E, Mehran L, Tohidi M, Azizi F. The prevalence, incidence and natural course of positive antithyroperoxidase antibodies in a population-based study: Tehran thyroid study. PloS one. 2017 Jan 4;12(1):e0169283. https://doi.org/10.1371/journal.pone.0169283

7. Pearce EN, Farwell AP, Braverman LE. Thyroiditis. N Engl J Med. 2003 Jun 26;348(26):2646-55. https://doi.org/10.1056/NEJMra021194

8. Dayan CM, Daniels GH. Chronic autoimmune thyroiditis. N Engl J Med. 1996 Jul 11;335(2):99-107 https://doi.org/10.1056/NEJM199607113350206

9. Staii A, Mirocha S, Todorova-Koteva K, Glinberg S, Jaume JC. Hashimoto thyroiditis is more frequent than expected when diagnosed by cytology which uncovers a pre-clinical state. Thyroid research. 2010 Dec;3(1):11. https://doi.org/10.1186/1756-6614-3-11

10.Thomas T, Sreedharan S, Khadilkar UN, Deviprasad D, Kamath MP, Bhojwani KM, Alva A. Clinical, biochemical \& cytomorphologic study on Hashimoto's thyroiditis. Indian J Med Res. 2014 Dec;140(6):729.
11. Sood N, Nigam JS. Correlation of fine needle aspiration cytology findings with thyroid function test in cases of lymphocytic thyroiditis. Journal of thyroid research. 2014;2014

https://doi.org/10.1155/2014/430510

12. Becker KL, Ferguson RH, McConahey WM. The connectivetissue diseases and symptoms associated with Hashimoto's thyroiditis. N Engl J Med. 1963 Feb 7;268(6):277-80. https://doi.org/10.1056/NEJM196302072680601

13. Chandanwale SS, Nair R, Gambhir A, Kaur S, Pandey A, Shetty A, Naragude P. Cytomorphological Spectrum of Thyroiditis: A Review of 110 Cases. Journal of thyroid research. 2018;2018 https://doi.org/10.1155/2018/5246516

14.Mariotti S, Anelli S, Ruf J, Bechi R, Czarnocka B, Lombardi A, Carayon P, Pinchera A. Comparison of serum thyroid microsomal and thyroid peroxidase autoantibodies in thyroid diseases. The Journal of Clinical Endocrinology \& Metabolism. 1987 Nov 1;65(5):987-93. https://doi.org/10.1210/jcem-65-5-987

15.Ghoraishian SM, Moghaddam SH, Afkhami M. Relationship between anti-thyroid peroxidase antibody and thyroid function tests. World J Med Sci. 2006; 1:44-7.

16.Iddah MA, Macharia BN. Autoimmune thyroid disorders. ISRN endocrinology. 2013 Jun 26;2013.

https://doi.org/10.1155/2013/509764

17. Sanyal D. Spectrum of Hashimoto's thyroiditis: Clinical, biochemical \& cytomorphologic profile. Indian J Med Res. 2014 Dec;140(6):710.

18.Bhatia A, Rajwanshi A, Dash RJ, Mittal BR. Lymphocytic Thyroiditis-is cytological grading significant? A correlation of grades with clinical, biochemical, ltrasonographic and radionuclide parameters. Cytojournal. 2007;4:10. https://doi.org/10.1186/1742-6413-4-10

19.Gayathri BN, Kalyani R, Harendra KM, Krishna PK. Fine needle aspiration cytology of Hashimoto's thyroiditis-A diagnostic pitfall with review of literature. J Cytol/Indian Academy of Cytologists. 2011 Oct;28(4):210. https://doi.org/10.4103/0970-9371.86353

20.Priyanthi Kumarasinghe M, De Silva S. Pitfalls in cytological diagnosis of autoimmune thyroiditis. Pathology. 1999 Jan 1;31(1):1-7. https://doi.org/10.1080/003130299105430

21.Devaka Fernando, The clinical epidemiology of thyroid disease in Sri Lanka, Journal of the Ceylon College of Physicians, 1997,30; 1 \& 2,22-26

22.Baker JR, Saunders NB, Wartofsky L, TSENG YC, Burman KD. Seronegative Hashimoto thyroiditis with thyroid autoantibody production localized to the thyroid. Ann Intern Med. 1988 Jan 1;108(1):26-30. https://doi.org/10.7326/0003-4819-108-1-26

23.Kapali A, Beerappa J, Raghuram P, Bangar R. Diagnostic accuracy of ultrasound imaging in Hashimoto's thyroiditis. Thyroid Research and Practice. 2017 Jan 1;14(1):28. https://doi.org/10.4103/0973-0354.200567

24.Rosairo S. Autoimmune Thyroiditis: Radiologist's point of view. Sri Lanka Journal of Radiology. 2016 Aug 25;2(1). https://doi.org/10.4038/sljr.v2i1.27 